\title{
THE DEVELOPMENT OF STRATEGIC MANAGEMENT PLANS FOR CONSTRUCTION EQUIPMENT, VEHICLES, AND TOOLS UNDER THE TRANSPORTATION POLICY TRANSFORMATIONS IN THAILAND
}

\author{
Preecha Soparat $^{1}$, Ornkamon Wangapisit ${ }^{2}$, and Surangkana Trangkanont ${ }^{2}$ \\ ${ }^{1}$ International Cooperation Group, Bureau of Planning, Department of Rural Roads, Bangkok, Thailand, \\ Tel: +6625515300, e-mail: preecha.soparat@gmail.com \\ ${ }^{2}$ Department of Civil and Environmental Engineering, Faculty of Engineering, Prince of Songkla University, \\ Songkhla, Thailand, Tel: +6674287015, e-mail: surangkana.t@ psu.ac.th
}

Received Date: December 14, 2020; Revised Date: May 7, 2021; Acceptance Date: August 19, 2021

\begin{abstract}
This article aims to propose the equipment, vehicle, and tool (EVT) management plans appropriate to the department of rural roads (DRR) in the current situation. This situation is influenced by the government policies that constrain human resources, with budget limitations and new forms of funding procedures. These factors along with technology advancement have challenged the DRR to establish an EVT management plan. To create the plan, the effective inquiry as part of design thinking is used to assess influences through the focus group and content analysis method. The results indicate that the DRR project development role is changed. This change results in four strategic management plans in the EVT. These strategic plans are concerning the EVT management system, EVT procurement and accessibility, unburden and support DRR staff, and finally EVT maintenance and disposal. Besides, the process of EVT strategic management plan development is described and more concerned with the engagement of the policymakers. Therefore, this report facilitates the other public agencies, particularly in the developing countries, in their plan development, based on multifactor real-world settings.
\end{abstract}

Keywords: Construction equipment, Design thinking, Public sector, Thailand, Strategic management plan, Vehicle and tool management

\section{Introduction}

According to article $65^{\text {th }}$ of the constitution of the Kingdom of Thailand, the Thai government had to identify the national strategic goals for sustainable development under good governance for the 20 years in 2017-2036. These goals served as a framework for integrating organizational strategic plans of all ministries and improved public accountability with fiscal budget efficiency and better value for money.

On the other hand, based on the Global Competitiveness Report 2015-2016, the Global Competitive Index ranks Thailand is $32^{\text {nd }}$, and the quality of roads in Thailand is ranked as $51^{\text {st }}$ among the 140 worldwide cases. The national logistics cost was $14.2 \%$ of Gross Domestic Product (GDP). The Thai government, therefore, announced the goals of increasing competitiveness, becoming a developed country, and achieving national stability, prosperity 
and sustainability under sufficiency economy philosophy [1]. To achieve these goals, the Ministry of Transport (MOT) is in a critical role as it manipulates all transportation systems. These systems are determinants of the economy of the country [2].

The Department of Rural Roads (DRR) is an organization under the MOT supervision, nationwide responsible for 3,280 routes with a total length of 48,031.391 kilometers [3]. Connectivity (to other transport modes), accessibility (to public services), and mobility (as detour or shortcut for resource movement) are significant outputs of this entity under the DRR's strategic goals of stability, prosperity, sustainability, and high-performance organization [2].

To take care of the road network, the main resources are known as equipment, vehicles, and tools (EVTs) are important, because their components are with the survey, construction, supervision, inspection, maintenance, and administration of the network. The investment in the EVTs is important because the cost is high and the advancement of technology in the equipment results in changes to construction methods, safety, cost efficiency, quality of work, and productivity [4-9].

However, the management of DRR's EVTs is currently based on day-to-day operations and preventive or corrective maintenances. The recording of EVTs applications and inventories is relatively poor, and they have been borrowed and transferred among the Bureau of Rural Roads (BRR). For example, some tools were completely lost and some equipment was damaged because of misuse.

Most EVTs are quite obsolete and were transferred from the Office of Accelerated Rural Development which was established in 1966 and dissolved in 2002. The rest are later self-procured or donated from other departments.

Nowadays, the DRR categorizes EVTs into 2 main groups, namely administration and office supplies, and fieldwork supplies. The former is composed of 5 subgroups and the latter comprises 7 subgroups as shown in Table 1.

The number in front of the subgroup name acts as code for the group. All of the type lists are owned by a variety of DRR's bureaus and divisions. The same type lists are differently manipulated due to different division-owning.

For example, under the same regional Bureau of Rural Roads (BRR), herein BRR12, trucks for road construction supervision and trucks for equipment maintenance are in charge by the Location and Design division and by the Mechanical division, respectively.

The first division can set the procurement and management directly through the BRR while the latter division has to request for such things through the Bureau of the Mechanical Equipment and Communications (BMEC), DRR's Head office.

This represents the lack of integrated EVT management, although the EVTs are used for supporting road construction. In addition, the number of competent operators, mechanics, and mechanical engineers is gradually reduced due to retirements and the government policy on the public human resources that limits the DRR's recruitment.

Another constraint is the limited budget and the new requirements for requesting a fiscal budget for organizational investment. The master plan of DRR's strategic plan is developed as a must before setting the fiscal organizational budget. 
Table 1. BRR's EVT Operation and Maintenance

\begin{tabular}{|c|c|c|c|c|c|c|c|c|c|c|c|c|}
\hline \multirow[b]{2}{*}{$\begin{array}{l}\text { Organizational } \\
\text { division in } \\
\text { BRR } 12\end{array}$} & \multicolumn{5}{|c|}{$\begin{array}{c}\text { Administration and Office } \\
\text { Supplies }\end{array}$} & \multicolumn{7}{|c|}{ Fieldwork Supplies } \\
\hline & 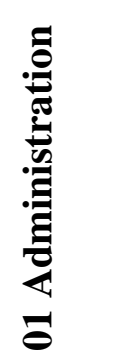 & 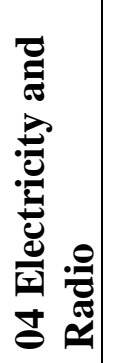 & 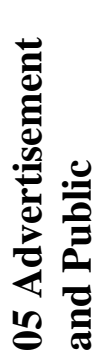 & 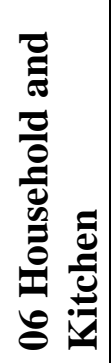 & 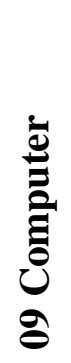 & 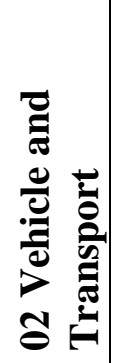 & 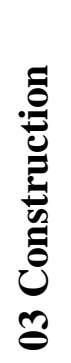 & $\frac{\overparen{E}}{\hat{\sigma}}$ & 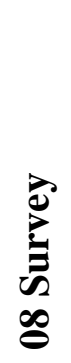 & 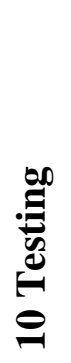 & 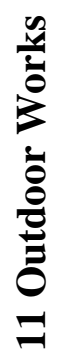 & 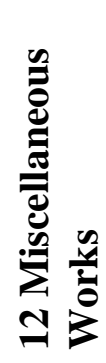 \\
\hline BRR Director & $*$ & $*$ & $*$ & $*$ & $*$ & $*$ & * & * & $*$ & $*$ & * & $*$ \\
\hline $\begin{array}{c}\text { Administratio } \\
\text { n and } \\
\text { Management } \\
\text { Division }\end{array}$ & $*, \mathbf{\square}, \Delta$ & $\begin{array}{l}* \\
\mathbf{a}, \Delta\end{array}$ & $\begin{array}{l}* \\
\mathbf{\square}, \Delta\end{array}$ & $\stackrel{*}{*}$, & $\begin{array}{l}* \\
\square \\
\Delta\end{array}$ & $*$ & $*$ & $*$ & $*$ & $*$ & $*$ & $*$ \\
\hline $\begin{array}{c}\text { Investigation } \\
\text { and Lab Test } \\
\text { Division }\end{array}$ & $*, \Delta$ & $\begin{array}{l}* \\
\text { a, } \Delta\end{array}$ & $*$ & $*$ & $\begin{array}{l}*, \\
\square, \\
\Delta\end{array}$ & $*, \Delta$ & $\begin{array}{l}*, \\
\square, \\
\Delta\end{array}$ & $*$ & $*$ & $\begin{array}{l}*, \\
\square, \\
\Delta\end{array}$ & $*$ & $*$ \\
\hline $\begin{array}{l}\text { Mechanical } \\
\text { Division }\end{array}$ & $*, \Delta$ & $\begin{array}{l}* \\
\text { घ, }\end{array}$ & $*$ & $*$ & $\begin{array}{l}*, \\
\square, \\
\Delta\end{array}$ & $\begin{array}{l}* \\
\mathbf{\square}, \Delta\end{array}$ & $*$ & $\begin{array}{l}*, \\
\square \\
\Delta\end{array}$ & $*$ & $*$ & $*$ & $*$ \\
\hline $\begin{array}{c}\text { Academic and } \\
\text { Technological } \\
\text { Transfer } \\
\text { Division } \\
\end{array}$ & $*, \Delta$ & $\begin{array}{l}* \\
\mathbf{\square}, \Delta\end{array}$ & $*$ & $*$ & $\begin{array}{l}*, \\
\square \\
\Delta\end{array}$ & $*, \Delta$ & $\stackrel{*}{\Delta}$ & $*$ & $\stackrel{*}{\Delta}$ & $*$ & $*$ & $*$ \\
\hline $\begin{array}{c}\text { Location and } \\
\text { Design } \\
\text { Division } \\
\end{array}$ & $*, \Delta$ & $\begin{array}{l}* \\
\text { घ, }\end{array}$ & $*$ & $*$ & $\begin{array}{l}* \\
\square, \\
\Delta\end{array}$ & $*, \Delta$ & $\stackrel{*}{\Delta}$ & $*$ & $\stackrel{*}{\Delta}$ & $*$ & $*$ & $*$ \\
\hline $\begin{array}{l}\text { Maintenance } \\
\text { Division }\end{array}$ & $*, \Delta$ & $\begin{array}{l}* \\
\square, \Delta\end{array}$ & $*$ & $*$ & $\begin{array}{l}* \\
\square \\
\Delta\end{array}$ & $*, \Delta$ & $\stackrel{*}{\Delta}$ & $*$ & $\stackrel{*}{\Delta}$ & $*$ & $*$ & $*$ \\
\hline \multicolumn{13}{|c|}{$\begin{aligned} \text { Remarks: * } & \text { Operation, } \\
& \text { - Self-maintenance, } \\
\Delta & \text { Outsourcing Maintenance such as Dealers }\end{aligned}$} \\
\hline
\end{tabular}

Although the DRR's EVTs are significant for DRR's core competences of land transport development, improvement, and maintenance, the EVTs management has been neglected for a long time. They have diversified and have been perceived as equipment and tools for implementing land transport execution. To achieve the organizational strategic goal of high-performance and the national strategies as well as to gain advantages from current technologies and innovations, and to overcome the limitations, the DRR aims to establish the strategic management plans of EVTs in 2019 by using the Design Thinking principles as a conceptual framework to create the plan. To develop this plan, the DRR also hired nationwide 
eight consultant teams as cooperators and coordinators to collect data through the Focus Group technique and conventional content analysis, to implement the principle. This plan development as the research objective aims at proposing the EVT management plans appropriate to DRR in its current situation. It is important to note that, the results do not only demonstrate the EVT management plans but also provide comprehensive knowledge on the development of public sector strategic management plans, particularly in the developing countries, with policy-maker engagement. This planning practice is rarely implemented in the real-world complexities of policy integration due to the characteristics of public organizational structure which is centralization. It is expected that this finding facilitates other public agents in practice in their organizational strategic plan development, under real-world policies.

\section{Literature Review}

\section{Equipment Management}

In road construction projects, there are a lot of equipment-intensive activities such as earthmoving, pavement construction, tunneling and pile construction [5, 9]. The availability of excavators, loaders, dozers, graders, trucks, and so on is a must. Sixty to seventy percent of road construction project cost is expenditures of purchasing, renting, operating, and maintaining of construction equipment [10]. The expansion in relevant construction equipment changes construction methods, increases productivity and safety, reduces costs, and improves work quality. Therefore, construction equipment is an important resource [4-9]. Managing equipment is crucial. The studies of 400 contractors in United State, 33 contractors in Saudi Arabia and the case studies in India and Ethiopia found that equipment management and policies are about need identification, alternative appraisal, financing approach and procurement, operation, maintenance, replacement, standardization, recording the historical data of equipment, inventory and safety $[6,8,10-11]$. Although the respondents were not in the public sector, the principles of management are similar because their management aimed to accomplish the organizational goals in terms of money (profitability or cost), capability (competitiveness or disaster relief), productivity, and safety. To understand the equipment management, it is, thus, important to recognize each of them step by step.

\section{Need Identification}

The acquisition of equipment aimed to perform the desired activities [8]. Predicting the future needed equipment and vehicles relies on past experiences on the activities and the entities' problems [10]. The need, generally, depends on the type of work, work volume, site location or paleogeography, bidding price, and new arrivals of equipment technology with user-friendliness [4-6, 10-13]. All of these factors implied the required equipment type, size, and specifications. Size could be measured by several performance parameters such as horsepower, standard operation weight, or bucket volume [9]. Head office or project managers proposed the required equipment [6].

\section{Alternative Appraisal}

According to the equipment identification, the decision-makers quantitatively and qualitatively compared alternatives $[6,8,11]$ in order to achieve better value for the business [10]. For the quantitative evaluation, these alternatives were investigated by using the cash flow of revenue and costs for calculating the current value of money in terms of net present value, accounting return 
on investment, internal rate of return, and payback period $[6,8,11,13]$. To some extent, the business ratio was also of concern due to its effecting on the organizational competitiveness in the industry $[6,11]$. In the case of the public sector, alternatives of procurement were evaluated based on the benefit to cost ratio because a non-profit organization can focus on cost minimization and the net socio-economic value of investment [14]. The value of alternatives exceeds a minimum rate of return were considered by top management and/or compared with the in-house historical records $[6,8]$. Acceptance or rejection depended on the top management expectation on the project investment [6] and on the models used to make a decision, namely the minimization of cost or the maximization of profit [10].

The revenue or benefit is in relation to the contract price or public interest as cash inflow. The total costs of equipment are composed of forecasted ownership and operating costs [9-10, 13, 23]. The former was related to initial capital cost, cost of investment known as interest, insurance cost, taxes, and storage cost. Furthermore, depreciation policy and salvage value in relation to economic life or useful life had also an effect on the cash flow. The latter was concerning the operation and maintenance costs during project execution. The operating costs varied depending on the working hours and type of equipment, and the physical shape and condition of the work location. These costs were considered and calculated based on the maintenance schedule, tire cost, and consumable costs such as fuel cost, and lubricating oil cost. Moreover, there were mobilization cost, operator cost, and cost of replacing spare parts [10,13]. The economic life of spare parts affected the equipment replacement decision and the equipment depreciation [8].

The issues qualitatively considered were management goals and policies such as ownership policy, funding capabilities, and long-term financial goals. These included employee safety and morale, company image, reputation, and perception to potential customers, and client requirements and expectations [6, 13]. Although the researchers did not explain why these qualitative considerations should be of concern, it is common that the sustainability of the entities depends on having proper organizational strategies based on the environmental competition. This includes the level of service driven by employee and customer satisfaction and trust.

\section{Financing Approach and Procurement}

As mentioned, top management usually made decisions on equipment acquisition based on qualitative and quantitative alternative appraisal and submitted it to the president for approval [6, 11]. However, some companies relied on the project or equipment managers to make decisions [11]. The number of individuals obviously involved in the procurement decision was high [4] due to the risk of investment forcing the companies to deliberate heuristic considerations in many aspects.

Three methods of equipment financing were used to procure, namely, an outright purchase based on the entities' capital, lease, and rental $[6,11,13,23]$. The rental value was the current cost attributed to the application of capital equipment [15]. The method had an impact on the entities' cash flow and financial status affecting the business ratio $[6,11,13]$. Regardless of the method used, the capital investment or expenditures on equipment must pay for themselves by generating revenue that exceeds the costs [13].

\section{Operation}

Operation performance depends on the capabilities of operators and equipment [10] as well as on the operating environment and the usage intensity [7, 13]. These operation factors had an effect on the conditions and useful life of the equipment [8]. The skills, discipline, and experience of 
operators and signalmen assisting the operators were crucial. Carelessness and attitude problems of operators lead to accidents [10] and damage to the equipment. In addition, operators' training, motivation, and extra-interests such as compensation insurance and so on, in their jobs were applied in human resource management in order to achieve competent employee retention $[6,10$, 13]. Equipment used in standard conditions and worked in its functional range $[5,13]$ would save costs in operation and maintenance.

\section{Maintenance}

Equipment deteriorated with age and usage and finally became ultimately non-operational $[7,16]$. The amount of wear and tear varied considerably between various equipment components and between various job conditions [7, 13]. Equipment maintenance was a significant activity because it minimized idle time, extended economic life, increased availability, and ensured a certain level of reliability $[6-8,13]$. The successful completion of construction projects, therefore, depended on reliable and functional equipment fleets [17].

There were 2 types of maintenances known as preventive and corrective maintenance. Preventive maintenance (PM) or scheduled maintenance was done based on schedule or hours of use or mileage. PM, therefore, decelerated the rate of equipment degradation and reduced the probability of failure [16]. Regular cleaning of a vehicle body, routine maintenance, and periodic wear determinations including timely attention to recommended services were the activities of PM [13]. PM was done by the owners' mechanics or operators depending on the size of the organization and fleet and the proximity of a workshop [6, 8, 11]. Operators' routine maintenance aimed to prevent loss of construction time or transportation cost of equipment delivery to dealer or workshop plant $[6,8]$. In the case of special needs, the dealer's mechanics took a maintenance role $[6,8]$.

Corrective maintenance $(\mathrm{CM})$ or overhaul maintenance or repair referred to rectifying a failure and restoring failed equipment to operational state $[7,16]$. Overhaul implied a major repair at a high cost of time and money [6], depending on the nature of the failure [7]. The productivity of equipment was very low and the equipment operation became uneconomical, even though some parts were replaced [6]. Equipment replacement is considered because of PM and CM costs, which are significant factors affecting equipment replacement decisions [13].

\section{Replacement and Disposal}

Equipment was replaced when it became inefficient, with high repair costs. The economic life is measured by economic studies. However, the final decision relied on not only formal analysis but also on the experience and subjective evaluation of intuitive decision-makers [6, 10, 13]. The parameters used in the analysis include inflation, depreciation, investment, maintenance and repairs, downtime, tax, obsolescence, and the time value of money $[6,11,13]$. Besides, the salvage value influenced replacement decisions in Saudi Arabia and India [6, 8]. In the real world, equipment replacement has a relation to new technologically innovative equipment, which may be superior to the replaced equipment in capabilities. This makes the replacement considerations and decision making more complicated [18].

The criteria used comprised accounting return on investment, payback period, net present value, and internal rate of return [11]. Moreover, there were methods of cost minimization, profit maximization, and mathematical modeling $[10,13,15]$. Based on the mathematical optimization of a cost function or a utility function, there was the opportunity cost model, the equilibrium models between operation and maintenance costs, the profitability models, and the 
replacement cost models [19]. The application of computers allowed practitioners to solve complex interrelated parameters in the mathematical models $[11,13]$. The determinants of the replacement decision, comparing equipment in use with available equipment in the market, were net cash flow [11] or comparative analysis of the operative machine capacity [19].

Regarding public agencies, their decision making is based on minimizing owning, operating, and maintenance costs of routine requirements and emergencies such as floods, landslides, and other natural disasters. The replacement, therefore, relied on the agencies' experience, resulting in replacing at a specified fixed amount of usage in terms of mileage or engine hours rather than those costs [13]. In other words, replacement after a fixed time or many repairs had normally been used [18].

There were a variety of equipment disposal methods of the used equipment that was replaced $[6,9,11]$ such as auctioning, trade-in to a dealer, selling to others, and so on. The price of the replaced equipment, known as residual value, was difficult to predict because of at the end of the ownership. This is ambiguous or uncertain among the equipment costs [9]. According to the accounting discipline, the residual value should be the book value. Initial equipment capital was deducted year by year based on the annual depreciation until the year that the equipment was to be sold [9]. This means the equipment had a book value [6]. Moreover, the locality affected the residual value due to region-specific market factors [17]. The residual values were presumed to be the intended value satisfying the owner based on his/her experience and also derived from distributor records from auctions [9]. In short, practitioners used their subjective experience to determine the suitable time, price, and location for equipment disposal [17]. Residual value, therefore, referred to the price of the piece of used equipment sold in the market at a certain time [9].

\section{Equipment Standardization}

Equipment standardization referred to the usage of similar equipment or equipment with the same elements [11] and auxiliaries with similar specifications and characteristics [23]. The main purposes of standardization were to minimize the operation and maintenance costs due to sufficient equipment capabilities, savings in parts inventory, better safety and relationship with the dealer, and easier administration over units $[6,11,23]$. The establishment and implementation of equipment and vehicle standardization, therefore, improved the equipment and maintenance management [10] because of repeatability and predictability [21]. Having standard elements implied that the mechanics and operators understood what they were getting and how to use the elements or spare parts [21].

\section{Equipment Data Record and Inventory Control with Spare Parts Management}

Data on equipment provided the fundamental information for managing the equipment and their spare parts inventory [13]. This included the analysis of equipment cost, and replacement [9]. Equipment was categorized, coded, and labelled with paint on the equipment, for security and individual operating records keeping [6]. The codes were based on equipment type, size, category, and entity in charge, and became registration numbers for recording [13]. A record consisted of manufacturer's name, model number, year of manufacturing, condition rating, size by HP, owning cost, operation time such as hours of use or age in years, and operating costs, purchasing date and price, and a brief description of special option attachments or other information [9, 13]. A diary or logbook recorded by the operator could help the equipment manager to track the equipment 
condition as he/she knows or is learning the behavior of the piece of equipment. The manager could, therefore, observe any unusual performance or maintenance needs of the equipment before it became a huge problem. Equipment managers also kept track of these elements for cost analysis [8]. This included equipment availability [13] because equipment significance is a function of its usage rather than of having it [22].

The availability of equipment was related to inventory issues. Different service levels of each equipment demanded different spare parts storage. Estimating the service level aimed to forecast critical demand. Some spare parts are, also, more critical in some locations than in others [22]. Keeping inventory records, making scheduled inventories of all eligible equipment, maintaining suitable storage of the equipment and guaranteeing safekeeping and giving custody, therefore, enable the entities in charge to maximize equipment availability, reduce spare parts inventory levels and operating costs, and guarantee productivity in the field. Inventory management was done by using paper-based records keeping [13] and with computer-based technology $[6,8,11,13]$.

\section{Equipment Site Safety}

The congestion of equipment working at a worksite could bring about hazards [12]. Several studies based on construction equipment showed that plants and types of machinery are primary causes of site accidents and injuries [23]. Moreover, operating equipment on a construction site was recently concern about air pollution by dust and emissions, vibrations, and noise that can negatively impact the operators [23]. In-house safety program with safety meeting on-site, and periodical examination of work procedures coupled with health and safety education of workers based on the procedures, therefore, improved safety performance, protected workers' health, and reduced accidents $[6,11,12,23]$. To some extent, safety was therefore perceived as a "profit center" because of savings from reduced property damage, employee injuries, and workers' compensation insurance premiums; these provided financial incentives to the entities in charge to help avoid accidents [13].

Although all studies reviewed provide discussion based on equipment management, the word 'equipment' also encompassed 'vehicles and tools'. This can be seen in the work of Atnew et al. [10] mentioning 'small vehicles, trucks, and equipment and vehicles standardization'. This included the study of Prajeesh and Sakthivel [8] regarding 'lab equipment'. Plant, equipment, and tools used in the construction industry are classified by price value namely 'Small tools and consumable', 'Equipment usually shared by a number of work activities', and 'Equipment used for specific tasks' [13]. Based on the definition of "Small tools and Consumables: Hand tools up to a certain value together with blades, drill, bits and other consumables ..." [13], laboratory equipment should be classified in this category. In addition, Seresht et al. [5] explained that equipment and tools as a category of the crew- and activity-level factors influence the productivity of equipment-intensive activities. Equipment, vehicles, and tools are managed similarly. In this research, the management of EVTs is, therefore, approached based on the fundamental equipment management studies.

\section{Design Thinking}

Design thinking (DT) was firstly published in 1969 and was known as the foundational work about the nature of design by Simon [24]. In the early days of the DT publication, the DT discourse was in the design-based of scholarly literature. After that, management academics conducted the 
design principle for business organizations. These brought about two discourses of the DT, namely 'designerly thinking' and 'design thinking (DT).' The former was related to the professional designer's practice and the latter involved design context which was used for other disciplines in the way of designers dealing with their works [24]. Under the design context, a designer normally has to simultaneously consider human needs, the availability of material and technical resources, and the opportunities and limitations of a project or business. These factors demanded the designer's abilities to be analytical and empathic, reasonable and sensational, and systematic and intuitive in order to accomplish their works. As a result, these dualistic aspects or paradox statements made the designer use his/her abductive thinking, which provided new and different perspectives and future possibilities [25-26].

The abductive thinking was visually expressed as a model of a perception-in-action process [25]. This model provided temporary and tentative ideas to the designer to understand the problems and create alternative solutions. Since the DT was a human-centered approach, the designer worked with colleagues, customers, end-users, and stakeholders as a team. Therefore, the effectiveness of creative and innovation processes was acceptable by all participants. The process of the DT model was similar to the design process. The design process started with a problem or challenge identification. Then, the ideas to overcome the problems/challenges were generated. The selected idea became the prototype of the problem-solving method. Finally, the prototype was evaluated [25]. With the simplicity of the design process and abilities to deal with complex problem situations of paradox statements as mentioned, several scholars from multidisciplinary proposed a variety of DT process models. All of them relate to empathy, definition, ideation, prototype, idea test, and implementation activities inspired by designers' work in a non-linear iterative process [24-27].

Regarding the management aspect, the DT is closely related to practice in the domain of management scholars [24]. The DT term was perceived that it provided the processes and toolkits helping multidisciplinary teams in any kind of organization to improve, accelerate, and visualize every creative process. In other words, it was understood as an approach of thinking bringing about transformation, evolution, and innovation to the new forms and new styles of management because it helped an organization to progress with more creativity and adaptabilities in innovation procedures [25]. Furthermore, the DT expressed the opportunity to apply such toolkits for problem-solving-contexts with the form of business, services, and processes. This form linked the creative design method to traditional business thinking, based on planning and rational problem solving [25]. Therefore, the outcome of the DT, in this context, was not new knowledge generation and theoretical or hypothesis test [27], but it was the improvement of services, products, and management. Under the DT principles, non-profit organizations, which lacked technical knowledge and human resources, could create sustainability and systematic long-term development [27].

As a result, the DRR used the DT principles as the foundational ground of research methodology because it is a useful process in organizational change and development [24] and provided the organizational management entities understand the concept of developing creative thinking [25]. This includes assisting interdisciplinary teams or organizations to tackle more complex problems [26], and engages with a novel problem situation by seeking for the central paradox [27]. In short, the DT is a way to define the problems in order to propose effective solutions brought about stakeholders' satisfaction since the DRR faced the challenges of the paradox statements. Human resource limitations, in terms of technical 
competency and the number of officers, coupled with the obsoleted EVTs under fiscal budget constraints has to be overcome to achieve the DRR's goal of the high-performance organization.

\section{Research Methodology}

To propose EVT strategic management plans appropriate to DRR in the current circumstances, under the constraints of human resource government policy, organizational conditions, and technology advancement, the Design Thinking (DT) principles are first applied as a foundation of Focus Group (FG) research methodology. The FG technique was used to collect data from topdown and bottom-up approaches to policy implementation. This included opened-questionnaires. Finally, all of these data collection methods were analyzed by using content analysis.

According to these DT characteristics and process models, the DRR applied them to create DRR's DT model for the EVT management scheme considered suitable for DRR's circumstances, shown in Figure 1. The model was used by all consultant teams in order to achieve consistency and reliability. The model process consisted of four main activities without ordering but with cycling dependent on the contextual reality. These activities were named Examination of existing reality, Identification of all expectations, Gap analysis, and DRR's EVT management plan.

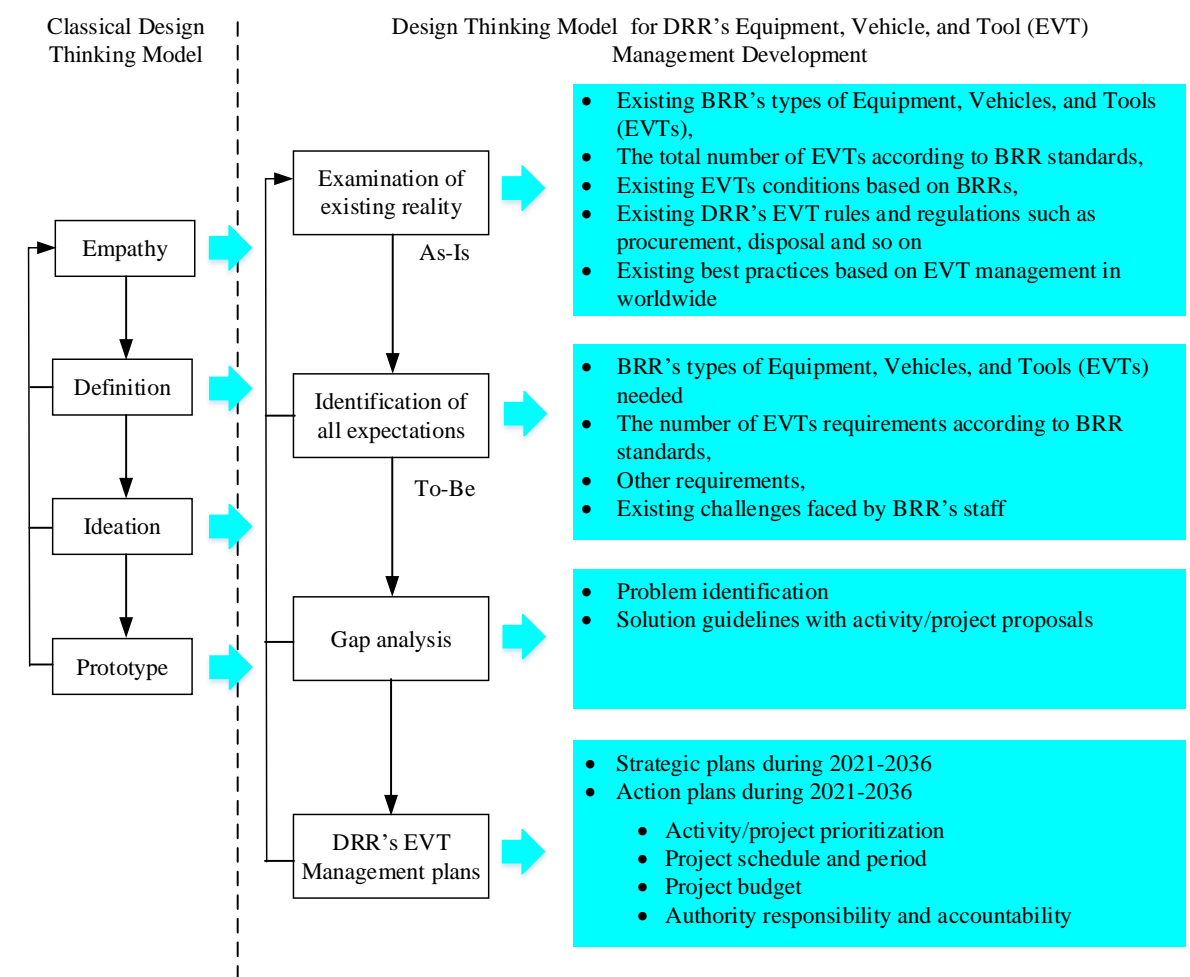

Techniques and Tools for Data Collection and Analysis Timeline

Focus group based on all heads of BRRs with DRR moderators and conventional content analysis

Three rounds

Focus group based on regional BRR with consultant moderator and two times of opened questionnaire disseminations and conventional content analysis Two rounds

Focus group based on subregional BRR staff with consultant moderators and conventional content analysis Three rounds

Focus group based on DRR's top management with consultant moderators and conventional content analysis

Four rounds

Figure 1. DRR's DT model for creating EVT management plan

The process based on the DRR's DT model started with the DRR's kick-off conference. DRR's management and staff consisting of 3 Regional Directors (RD) and 3 secretaries from BRR 11, 12 and 14, a Director of the International Cooperation Group (ICG) and 2 ICG staff, 2 representatives from the BMEC, 1 representative from the Bureau of Training 
(BT), 1 representative from the Bureau of Road Safety (BRS) and eight consultant teams were invited to participate. DRR moderators described what problems and challenges DRR encountered based on government policies in terms of budgeting, human resources, and procurements. Besides, the emergence of technology advancements took a significant role in DRR project execution regarding supervising, monitoring, and inspecting. As a result, the DRR project development would gradually result in ineffectiveness. The DRR moderator then encouraged all participants as the first focused group on the management level to participate and discuss to identify the particular issues that they faced. The consultant teams as observers tried to understand them.

The conventional content analysis was used by the consultant teams to record, annotate, codify, and classify their expression based on themes or patterns. This analytical method was used because it provides the phenomenon which is used to design a study [20] being similar and compliant to the DT.

The FG method was used because of several reasons. First of all, it is advisable to develop drafts of questionnaires. Second, it is appropriate to use for evaluating situations based on participants' perception., Third, it is suitable to provide the interpretations of the participants' results from the previous meeting. Finally, it is easily done by gathering people of similar backgrounds in a group, generating a familiar environment for spontaneous expression, and facilitating the interactions among the participants; all at a reasonable cost [28-30].

According to the kick-off conference, the codification and classification were used to develop an open structure questionnaire based on the EVT types and characteristics with definition including DRR staff's existing and upcoming problems and challenges. The follows were the examples of questions in the questionnaire:

- Please lists the BRR's EVT details based on the year of buying, EVT code, where was each EVT in place and why, department owner, EVT condition based on availability, repair and idle.

- How many type of EVT that the BRR need and for what purpose?

- What were the problems for EVT recruitment and allocation?

- How do you solve the EVT recruitment and allocation problems?

After the conference, each consultant team arranged meetings based on regions and sub-regions. The first session aimed to provide the information on DRRs' challenges and problems to all BRR staff. Then in the second session, only the staff of regional BMEC as the focus group on an operational level working with heavy construction equipment were firstly invited to contribute their experiences, perceptions, attitudes, ideas, and events based on their operation and maintenance works. All BMEC staff had often worked together as colleagues and had got used to one another. This brought about a friendly discussion environment. A regional consultant based on construction management professional was a moderator due to expertise in construction equipment management. After that, other staff working for other regional divisions were invited to share their practices, feelings, opinions, knowledge, and cases based on their works on current vehicles and tools.

The first draft of the open structure questionnaire was then disseminated to the regional BMEC and other division staff at the end of every meeting and allowing them to spend time understanding and asking questions. All the participants understood all questions in the questionnaire, so these questionnaires were then requested to be sent back to the regional 
consultants two weeks later. After that, the regional consultants summarized both qualitative and quantitative data and sent them to the $8^{\text {th }}$ consultant team for summarizing the data nationwide. This summary was presented to the DRR top management to induce a discussion among them. The top management consisted of a deputy direct of DRR, 3 Regional Directors (RD) and 3 secretaries from BRR 11, 12 and 14, a Director of the International Cooperation Group (ICG) and 2 ICG staff, 2 representatives from the BMEC, 1 representative from the Bureau of Training (BT), 1 representative from the Bureau of Road Safety (BRS). Based on the FG method, the consultant team became the facilitator explaining questions to the management and observing their discussion. A variety of issues raised were collected and then coded. The meetings of all levels of DRR staff as focus groups aimed to achieve the top-down and bottom-up approaches. According to these approaches, technical rational analysis is based on rule and regulation structure and on context-specific factors at the ground level where the public services are delivered [31]. This research method of planning development was rarely implemented as mentioned in the study of Marsden and Reardon. They indicated that most top management as policy-makers seldom participated in reflecting the feasibility of the strategic management plan in the transportation study [31].

The implementations of the FG had been done several times, while the opened questionnaire was modified for more detail. The study was finished because the data reached the level of saturation, in that there was no new information. At this level, there, finally, were 4 rounds of focus groups on the top management, 3 rounds of focus groups on the head of DRR's management, 2 rounds of focus groups on regional BRR and BMEC staff, and 3 rounds of focus groups on sub-regional BRR and BMEC staff. The open structure questionnaires were, also, disseminated twice. Each meeting was also divided into 2-3 sessions depending on the participants' time availability. The time spent in each session was 2-3 hours. The duration of the study was 10 months.

\section{Results and Discussion}

The results provided a comprehensive view of the situations faced by the DRR's EVT management. The problems of EVT management were in part derived from DRR change in its role. Currently, the fiscal budget on DRR's project self-execution was only ten percent of DRR's total budget of the project procurement. This coupled with the government policy limiting human resource recruitment aiming to reduce the burden of retired officers' pension on fiscal budget resulted in changes to the DRR's organizational strategic management plan. The DRR's project execution role was shifting from operator to regulator, as illustrated in Figure 2. This plan aimed to increase the role of project development regulator and simultaneously reduce the role of project development operator within 20 years. Under the regulator role, DRR emphasized road safety and maintenance and promoted local authority for road development. This caused the EVT management to be neglected, especially regarding heavy construction equipment, although clearly, the EVTs were essential.

Regarding the DRR's EVTs, most of them were quite obsolete and difficult to fix with only an update. Insufficient EVTs led to purchasing and procurement. The EVTs were purchased as in mass volumes for cost-effectiveness and compliance with public rules and regulations. However, they were not suited for all geographic localities, and EVT allocation did not have prioritization. This situation brought about borrowing EVTs among BRRs. Furthermore, the borrowing process had a time delay, due to DRR's functionally bureaucratic structure. Therefore, 
the available EVTs were misused to address urgent problems such as floods, soil erosion, and landslide causing road damages. There was no EVT consistently recorded and staff in charge were shifted every 2-3 years due to promotion and so on. These were perceived there was having no EVT management, even though there was EVT coding and recording. These problems became a vicious cycle that intensified, as shown in Figure 3. As a result, nine EVT management plans were purposed to remedy this cycle according to the DRR's role change. These plans were categorized based on the management aspects of EVT administrative management, EVT recruitment and allocation management, EVT human resource management, and EVT replacement management. These categorizations aimed to facilitate the DRR's EVT management for planning, organizing, directing, controlling and resource identification and allocations.

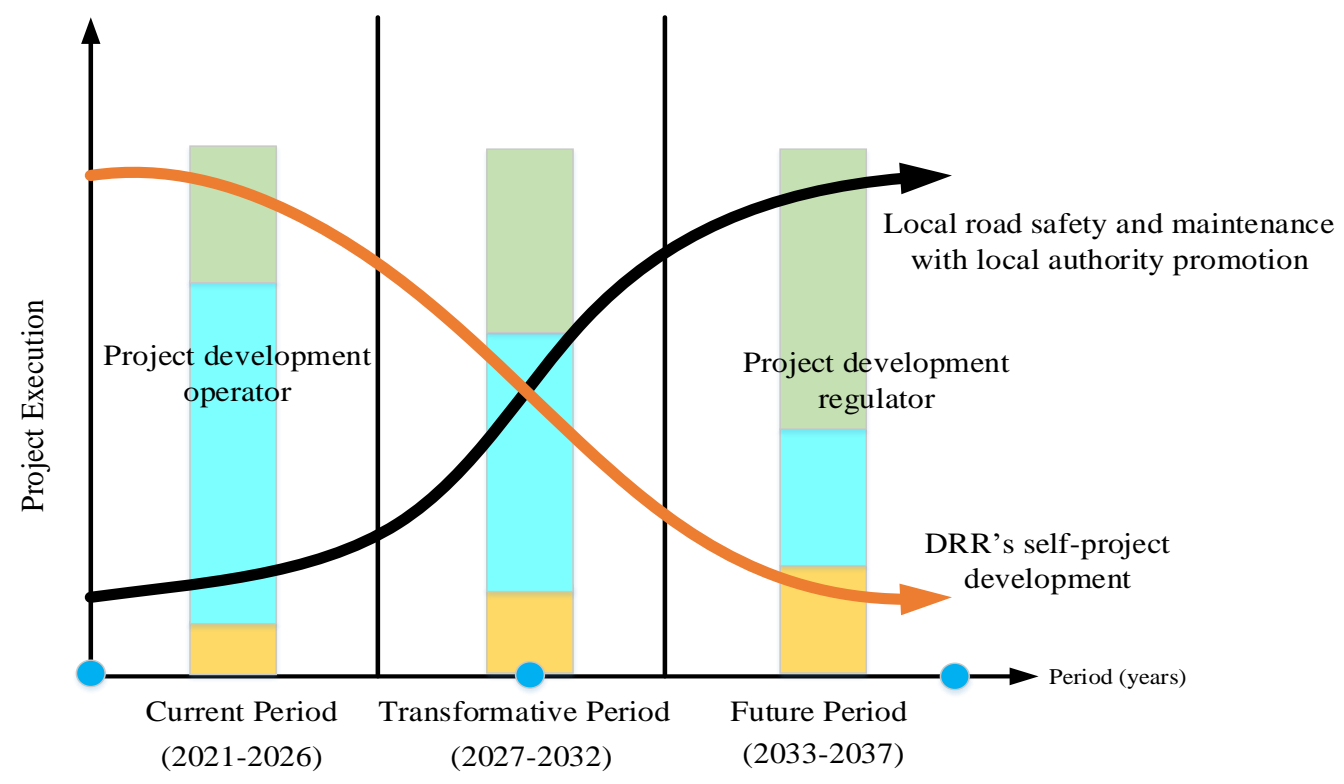

Road Safety

Road Construction

Road Maintenance

Figure 2. DRR's roles in project development

After the categorization, each category was name and became the DRR's EVT management strategic plans. All these management strategic plans were grouped again and became a DRR's EVT master plan. As a result, under the DRR's EVT master plan, there were four management strategic plans, namely, the EVT Management System and Budgeting, the EVT Procurement and Accessibility, the Unburdening and Supporting DRR Staff, and the EVT Maintenance and Disposal.

\section{The $1^{\text {st }}$ Strategic Management Plan: 'EVT Management System and Budgeting'}

This strategic management plan consisted of an action plan or management plan which was labelled as 'EVT management for planning, organizing, controlling, monitoring, and evaluating'.

To date, all DRR's EVTs have been coded and indicated based on EVT type and categories, BRR in charge with the region, and year of production. The operation and maintenance of EVTs are recorded in terms of date, consumables, engine mile, and so on. These data are recorded 
for accounting rationales but cannot be analyzed and modelled to forecast EVT service life and implement EVT management. There was no DRR's EVT management properly implemented.

This 'EVT management for planning, organizing, controlling, monitoring, and evaluating' action plan is generated and aimed to track the EVTs in terms of product life cycle and execution. EVT dealers, types, size based on capacity and engine, specifications, year of procurement, location, codification, service life, depreciation scheme, operation and maintenance dates and periods, and so on, were recorded in the information system. The EVT records keeping is important, as seen in the work of Shash and Ghazi [6] in which more than $85 \%$ of equipment contractors maintained accurate usage logs to closely monitor their equipment. This is because a good records system increased the ability of operators to accurately estimate the output, and ability of mechanics for preventive and corrective maintenance forecast, in order to achieve a balance between EVT reliability and availability.

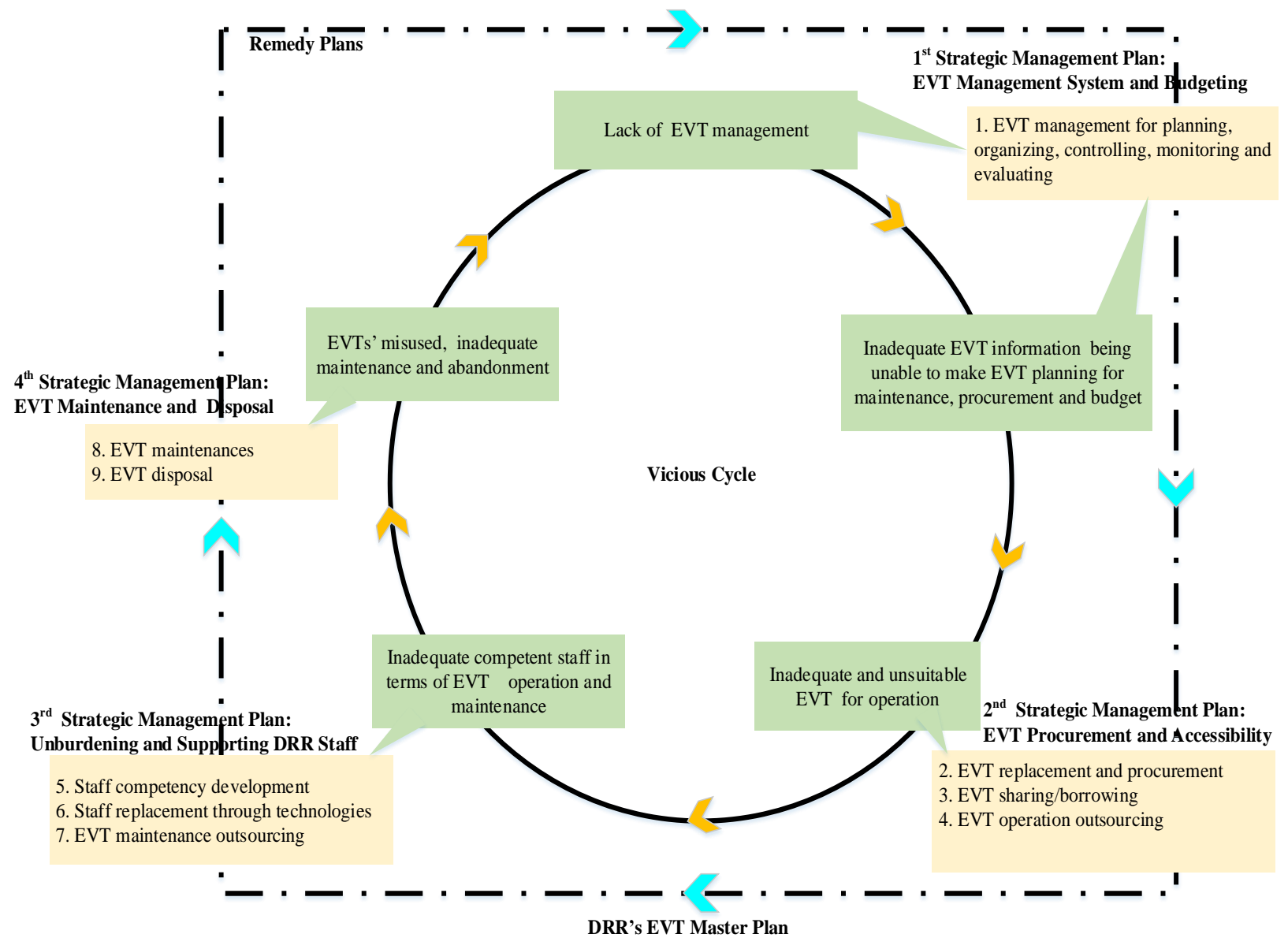

Figure 3. DRR's EVT master plan based on the vicious cycle

Information technology can be used for collecting and storing data. Computers can be used for statistical data analysis, modeling, and analyzing, to achieve optimal decisions [7]. As a result, during the current period, the DRR as a project development operator can use a free application for data collection, based on for example Google sheets, for data recording in the cloud system. Data access security can be managed through email registration. The DRR staff can use it for recording and tracking each EVT. Moreover, the emergence of radio frequency 
identification (RFID) coupled with a global positioning system (GPS) can be used to track EVT location [12]. In addition, the training program should be provided to all staff. By using these technologies, the DRR staff can know the EVT location, availability, and condition. The DRR staff can spontaneously access the system in real-time. The DRR's EVT operators/users/mechanics can access to the system for recording/reporting their operation and maintenance works. DRR's supervisors/management can use the data for decision making of EVT budget or replacement. The DRR can use an Enterprise Resource Planning software application as well, however, this alternative is quite expensive and demands programmers who are familiar with the DRR's resource management system to install DRR's massive data. The services after sale should be considered in this context.

\section{The $2^{\text {nd }}$ Strategic Management Plan: 'EVT Replacement and Procurement'}

This strategic management plan consisted of three action plans and was labeled 'the EVT replacement and procurement, the EVT sharing and borrowing, and the EVT outsourcing for operation'.

According to the 'EVT replacement and procurement' action plan, DRR's EVT replacement, currently, depends on intuitive judgments. DRR's intuitive method echoed the study of Gransberg et al. [13]. They indicated that this method was the most predominant one for deciding the EVT replacement because of its simplicity and reliance on individual judgment. Regarding the EVT procurement, it depended on fiscal budget availability. The process of disposal is also bureaucratic. An operator proposed a list of EVT disposals to the chief of the department. After examination, the chief proposed it to the head of BRR. The head then sets a committee to decide between the disposal through a donation to local authorities, museums, auction, or continued use. These EVT acquisition and disposal principles were slightly different from the findings of Shash and Ghazi [6] and Tavakoli et al. [11]. This may be because of the difference between the public and private sectors' organizational size, objectives, and policies. Private contractors' replacement decisions depended on top management for the final decision which relied on qualitative and quantitative analysis. The DRR used intuitive methods and ensured the disposal of the EVT by hierarchical organization structure and committee. Difficulty with documenting the EVT disposal made the replacement also delayed. Therefore, most BRRs wait for fiscal budget remains, which are uncertain.

In the case of an urgent situation, such as a natural disaster causing road damage, a BRR or local authority borrows from other BRR's EVTs to repair the road. Once the EVTs are returned in damaged condition, the BRR possessing the EVTs is unable to recover the costs of fixing. The EVT outsourcing for an operation is quite difficult because outsourcing procurement needs project establishment. Budgeting and scheduling are clarified and proposed. All of these issues caused DRR to have changes in its role, and to rethink the EVT procurement and accessibility for application. This finding was quite new since most scholars studied in equipment management for private sector. There was rarely mention in the equipment borrowing issue.

During the current period of 2021-2026, it is a necessity for each BRR to have a full capacity of the EVT reference frame for BRR's project execution. Even though the DRR now in total provides a project development budget of only ten percent of its fiscal budget, with the weakness of local authorities, the DRR as their mentor has to prepare itself for supporting them. Therefore, the first action plan of the second strategic plan aims to fulfill such duty, and each BRR's requirements gained from the questionnaires. 
As a result, for the 'EVT sharing and borrowing' action plan, the criteria of EVT sharing and borrowing should be based on a cost minimization scheme as public service providers [13]. Checking the EVT condition before and after borrowing across the organization has become a must. The borrower has to pay not only for operating costs but also owning costs.

Regarding the action plan of 'EVT outsourcing for operation', the DRR had some emphasis on this issue. This might be because according to Thai values, the grateful relationship, and flexibility and adjustment coupled with interdependence orientation [32] make the outsourcing on the activity base easy. Most of DRR's contractors are willing to help the DRR in unexpected situations such as road damage due to flood. They do it because they think this psychological investment brings about unrestricted project inspection and next project procurement. On the other hand, if they reject cooperating with the DRR, they will face difficulties in working with DRR regarding the Thai values of ego and face-saving. This is because, in Thai practice, right or wrong do not depend on the rules but depend on who you are or whom you know [32].

During the transformative period of 2027-2032, the DRR has to gradually unburden its work in a project development role and prepare itself for the new role of regulator. The DRR has to do a work breakdown structure (WBS) by identifying DRR activities and work package based on the regulator role. According to these activities/work packages, the EVTs used for these have to be listed and described for their specifications in order to prepare for purchasing or procurement. The number of EVTs for project execution is reduced while the local authority is strengthened, the DRR problems derived from the EVT sharing and borrowing, or EVT outsourcing for the operation will automatically decrease.

\section{The $3^{\text {rd }}$ Strategic Management Plan: 'EVT Unburdening and Supporting DRR Staff'}

This strategic management plan is composed of three action plans and was labeled 'Staff competency development, Staff replacement through technologies, and EVT outsourcing for maintenance'.

To date, the DRR's general practice in project development starts with surveying followed by design. After that, they assess project feasibility and prioritization based on qualitative and quantitative approaches. They then decide to perform the prioritized project by themselves, or write terms of reference (TOR) for open bidding, depending on project value and capabilities. As mentioned, the DRR now totally executes the project development with only ten percent of the fiscal budget. Most DRR's works are to regularly perform activities of surveying, designing in detail, writing TOR, tendering, inspecting the project execution, and approving milestone payments, operating, and maintaining completed projects. To some extent, the completed projects are submitted to a local authority for operation and maintenance. The role of DRR's project development as an operator is quite small, while the role of DRR's project development as a regulator is quite high. The number of DRR staff is simultaneously declining. In particular, the BMEC staff are currently unable to manage with their out-of-date engines, because the BMEC staff competent with those engines are mostly retired. Furthermore, all DRR staff get used to the existing EVTs but they will have to comply with the new EVTs based on DRR's regulator role soon. Therefore, the selection of the new EVTs should increase the DRR staff productivity through advanced technologies. These technologies demand the DRR staff to be trained for applications. 
As a result, the first action plan of 'Unburdening and Supporting DRR Staff' strategic management plan is 'Staff competency development'. During the current period of 2021-2026, the DRR intends to implement the training program in order to develop DRR's staff competencies based on existing EVT operation and maintenance. The best practices in one region can be transferred to other regions through seminars, focus groups, and ultimately through online training programs, or by setting a DRR's knowledge-sharing platform network. In addition, training-on-the-job among the DRR staff should be considered.

With regard to the action plan of 'Staff replacement through technologies,' this plan was prepared to the 'transformative to future' period of 2026-2037. Based on WBS as mentioned in the second strategic management plan, the new EVTs listed are considered in the line with other public organizations' technology applications and acceptability. The DRR staff can be trained in terms of their operation and maintenance by dealers of the new EVTs. This includes knowledge sharing with other public organizations.

For example, the Department of Lands (DOL) now uses a real-time kinematic global navigation satellite system (RTK GNSS) network for mapping and title deeds, due to its accuracy reducing land ownership disputes among entities. This RTK GNSS network needs continuously operating reference stations (CORS) for signal linkage, the control center for data processing and backup, users' location as a virtual reference station, and a wireless communication technology base. The DOL has 223 CORSs [33]. Regarding survey activities, a total station, integrating optical and electronic levels, and machine automation systems used for leveling, reference stationing, contouring, and so on, becomes more intelligent. This intelligent total station is not only able to perform the total station required tasks but also can 3D scan, digital imagery, perform data processing for calculating a parcel of land area or work volume of the tunnel, provide a global navigation satellite system (GNSS) connectivity, and so on. As a result, the application of intelligent stations coupled with the RTK GNSS network system should bring about improved DRR staff's productivity, reliability, and accuracy in survey and design work.

Another example relates to project inspection. Roller-integrated compaction monitoring (RICM) technology has been used for compaction measurement in earthwork and hot mixed asphalt construction in several countries [34]. The RICM refers to sensor measurements integrated into compaction machines. The RICM system coupled with the latest technologies of sensors, computers, and GPS results in data on density, compaction, and modulus- or stiffness-based measurements in real-time. Therefore, DRR's TOR of project procurement should be written on RICM specifications for quality assurance and control during earthwork and pavement construction. By using these technologies, the second action plan of DRR staff replacement through technologies is also responded to.

For the 'EVT maintenance outsourcing' action plan, this scheme aimed to support the EVT maintenance and disposal strategic plan. During the current period, re-hiring retired DRR staff should be necessary, since they are familiar with the existing EVTs. The new EVTs should have service after-sale contract agreements.

Generally, the maintenance service after the sale is based on mileage or years of usage and is provided through the dealers. However, it is not clear that once that service has expired, the maintenance service providers of the new EVTs should be the dealers or local shops/garages, because of the wide variety of the DRR's EVTs. 


\section{The $4^{\text {th }}$ Strategic Management Plan: 'EVT Maintenance and Disposal'}

This strategic management plan is composed of two action plans and was labeled 'EVT maintenance, and EVT disposal'.

The maintenance scheme of DRR's EVTs consists of preventive and corrective types of maintenance. The former has been done based on mileage or operating hours of equipment and vehicles. The latter has been implemented based on malfunctions. When the corrective maintenance of EVTs fails, the EVTs were abandoned in a warehouse due to the difficulties with EVT disposal. Moreover, change in fiscal budget conditions demanded that the DRR created a strategic plan for EVT maintenance. As a result, the DRR establishes a strategic management plan for EVT maintenance and disposal.

The first action plan of the 'EVT maintenance' was expected to upgrade all EVT capabilities to accomplish the DRR's strategic goal of the high-performance organization in the current period or EVT useful life. Since the new EVTs for the transformative and future periods were not identified yet, the DRR presumed the maintenance budgets of the new EVTs based on the number of the existing EVTs in the master plan. Some of these existing EVTs would be replaced with new EVTs. All the existing EVTs were listed to make the budget about EVT maintenance about the EVT preventive maintenance costs recorded and the BRR estimation of corrective maintenance costs. These costs depended on the characteristics of each EVT. For example, the maintenance costs of an excavator were listed based on the fiscal year. The preventive maintenance cost was estimated per year based on the costs of lubricating oil, filters, ring rubber, and so on. The track or wheel was replaced every 8 or 5 years, respectively. The cost of the track/wheel was evaluated and added to other costs according to service life. The corrective maintenance costs and year of maintenance execution were determined by the BMEC staff. Furthermore, the rationale of maintenance was also explained. Therefore, two action plans of maintenance schemes with the budget were proposed.

For the action plan of the 'EVT disposal,' the existing EVT disposal was limited by the DRR's rules and regulations, particularly for construction equipment and vehicles. The number of people involved was largely due to the low frequency of acquisition [4]. The DRR, therefore, disposed of the equipment and vehicles broken down. The DRR established a certain service life for equipment and vehicles, as the basis for eliminating. This service life depends on the type of EVTs. For the usable equipment and vehicles that exceeded the expected service life, the DRR allows BRR to decide between purchasing /or continued use. For the transformative and future period, the DRR has to consider EVT disposal in terms of durability and compatibility with technologies that are rapidly changing.

\section{Conclusions}

Rapid changes in Thai government policy coupled with DRR's human resource restrictions resulted in dramatic changes in DRR strategic management. One of the significant changes was in DRR's EVT management due to large investment costs. The technologies involving EVTs have been currently innovative. These demanded the DRR find out new approaches to EVT management that had been neglected for a long time. Design thinking concept was used to the foundational ground for finding the root causes of problems in both rule and regulation structures, and context-specific factors, through focus group data collection and content analysis. The results showed that the DRR changes in project development role brought about four EVT strategic 
management needs, in order to achieve the DRR's strategic goal of the high-performance organization. The first strategic management of EVT management system and budgeting aimed to track EVT information in terms of EVT performance, to support the EVT budget planning and tools for decision-making. The second strategic management of EVT procurement and accessibility emphasized DRR's EVT availability. The third strategic management focused on promoting DRR staff's competencies through knowledge management and technologies. Finally, the purpose of the strategic management of EVT maintenance and disposal was to establish a maintenance budget and eliminate the bureaucratic process of EVT disposal. Although there was no clarity in the new EVT maintenance program because it depended on the WBS based on the DRR role of project regulator and uncertain technologies, the DRR put at least an effort in the maintenance budget. This budget as a resource commitment provided the DRR volume for creating a suitable maintenance program in the future.

The outputs of this study were the EVT management plans and contributed comprehensive knowledge of public sector strategic management plan development with policymaker engagement. The key factors derived from the national policy and public organizational strategic goal as well as the complexities in operational practices were used to develop strategic management plans. The top-down/bottom-up approaches through the participation of multilevel and cross-sectional staff within the organization brought about the advent of new EVT management and implementation. The DRR's staff understand the holistic view process of strategic management development and the challenges with this development in real-world situations. This practice has been rarely implemented in most previous studies, particularly, the participation and engagement of policy-makers coupled with operational staff in planning development. These improved not only the DRR performance but also implied the methods of plan development for other agencies, particularly in the developing countries where deliberative bureaucracy system is not prevailing. Other public organizations could use this approach as a template to create organizational management plans in practice.

\section{Acknowledgement}

This study was funded by the Department of Rural Roads (DRR). The authors are grateful to the Bureau of Planning, Bureau of the Mechanical Equipment and Communications, and all the BRR officers for suggestions and discussion. The data used for analysis were mainly provided by the Bureau of the Mechanical Equipment and Communications, Bureau of Planning, BRR officers, and all the consultant teams. Their efforts to solve the vicious cycle of DRR's problems are invaluable and beneficial. The interpretation, description, and discussion in this paper are solely those of the authors and are not intended to represent the data providers. The authors would also like to thank Research and Development Office (RDO) - Publication clinic for proofreading cooperation and Seppo Karrila for his language editing and diligent proofreading of this article.

\section{References}

[1] Office of Transport and Traffic Policy and Planning, Strategic Plan under Major Mission of the Ministry of Transport under (draft) Strategy for the Development of the Thai Transportation System for 20 Years (2017-2036) [Online], Bangkok, Thailand, 2016 Available: http://www.otp.go.th/uploads/tiny_uploads/PolicyPlan/1-PolicyPlan/25600316OpertionPlan/25600316-OpertionPlan3.pdf [Accessed: Feb. 22, 2020] 
[2] N. Suksuwan, and S. Trangkanont, "The conceptual framework of the governmentsponsored rural road improvement project evaluation and selection," Engineering Journal, Vol. 22, No. 1, pp. 109-129, 2018. doi: https://doi.org/10.4186/ej.2018.22.1.109

[3] Bureau of Maintenance, Rural Road Network: For Fiscal Year 2020 [Online], Bangkok, Thailand 2019: Available: https://maintenance.drr.go.th/wp-content/uploads/2019/12/drr2019-12-23_09-27-51_076997.pdf [Accessed: Apr. 26, 2020].

[4] D. Arditi, S. Kale, and M. Tangkar, "Innovation in construction equipment and its flow into the construction industry," Journal of Construction Engineering and Management, Vol. 123, No. 4, pp. 371-378, 1997. doi: https://doi.org/10.1061/(ASCE)0733-9364(1997)123:4(371)

[5] N.G. Seresht, and A.R. Fayek, "Dynamic modeling of multifactor construction productivity for equipment-intensive activities," Journal of Construction Engineering and Management, Vol. 144, No. 9, pp. 1-15, 2018. doi: https://doi.org/10.1061/(ASCE)CO.1943-7862.0001549

[6] A.A. Shash, and S.Ghazi, "Construction equipment management practices of major contractors in Saudi Arabia," Journal of King Saud University - Engineering Science, Vol. 16, No. 1, pp. 61-81, 2003. doi: https://doi.org/10.1016/S1018-3639(18)30780-3

[7] D.N.P. Murthy, A. Atrens, and J.A. Eccleston, "Strategic maintenance management," Journal of Quality in Maintenance Engineering, Vol. 8, No.4, pp. 287-305, 2002. doi: https://doi.org/10.1108/13552510210448504

[8] V.P. Prajeesh, and N. Sakthivel, "Management of equipment \& machinery in construction," International Journal of Innovative Science, Engineering \& Technology, Vol. 3, No. 5, pp. 113-118, 2016.

[9] G. Lucko, and M.C. Vorster, "Predicting the residual value of heavy construction equipment," Paper presented at the Fourth Joint International Symposium on Information Technology in Civil Engineering, November 15-16, 2003, ASCE Library, Nashville, Tennessee, United States, 2004. doi: https://doi.org/10.1061/9780784407042

[10] S.M. Atnaw, L. Singh, and A. Yousuf, "Road construction equipment management: A case study on selected industry," International Journal of Engineering Technology and Science, Vol. 5, No. 1, pp. 91-97, 2016.

[11] A. Tavakoli, E.D. Taye, and M. Erktin, "Equipment policy of top 400 contractors: A survey," Journal of Construction Engineering and Management, Vol. 115, No. 2, pp. 115317, 1989. doi: https://doi.org/10.1061/(ASCE)0733-9364(1989)115:2(317)

[12] N. Pradhananga, and J. Teizer, "Automatic spatio-temporal analysis of construction site equipment operations using GPS data," Automation in Construction, Vol. 29, pp. 107-122, 2013. doi: https://doi.org/10.1016/j.autcon.2012.09.004

[13] D.D. Gransberg, C.M. Popescu, and R.C. Ryan, Construction Equipment Management for Engineers, Estimators, and Owners, CRC Press, New York, United States, 2006.

[14] P. Soparat, N. Suksuwan, and S. Trangkanont, "The integrated appraisal framework of rural road improvement projects," Engineering Journal, Vol. 23, No. 3, pp. 117-140, 2019. doi: https://doi.org/10.4186/ej.2019.23.3.117

[15] J.M. Malcomson, "Replacement and the rental value of capital equipment subject to obsolescence," Journal of Economic Theory, Vol. 10, No.1, pp. 24-41, 1975. doi: https://doi.org/10.1016/0022-0531(75)90059-9

[16] J. Pongpech, and D.N.P. Murthy, "Optimal periodic preventive maintenance policy for leased equipment," Reliability Engineering \& System Safety, Vol. 91, No. 7, pp. 772-777, 2006. doi: https://doi.org/10.1016/j.ress.2005.07.005 
[17] C. Liu, Z. Lei, D. Morley, and S.M. AbouRizk, "Dynamic, data-driven decision-support approach for construction equipment acquisition and disposal," Journal of Computing in Civil Engineering, Vol 34, No. 2, pp 1-12, 2020. doi: https://doi.org/10.1061/(ASCE)CP.19435487.0000871

[18] M. Subhash, and K. Damian, “A Strategy for optimal equipment replacement," Production Planning and Control, Vol. 14, No. 6, pp. 571-577, 2003. doi: 10.1080/09537280310001613740

[19] W.A.S. Casto, O.D. Castrillón, G. Gonzales, and A.V. Folleco, “A multi-criteria application for an equipment replacement decision," Ingenieria y Desarrollo, No. 25, pp. 80-98, 2009 [Online]. Available: http://www.scielo.org.co/pdf/inde/n25/n25a05.pdf

[20] H.-F. Hsieh and S.E. Shannon, “Three approaches to qualitative content analysis," Qualitative Health Research, Vol. 15, No. 9, pp. 1277- 1288, 2005. doi: https://doi.org/10.1177/1049732305276687

[21] A.G.F. Gibb, and F. Isack, "Client drivers for construction projects: implications for standardization," Engineering, Construction and Architectural Management, Vol. 8, No. 1, pp. 46-58, 2001. doi: https://doi.org/10.1108/eb021169

[22] R. Dekker, M.J. Kleijn, and P.J. de Rooji, "A spare parts stocking policy based on equipment criticality," International Journal of Production Economics, Vol. 56-57, pp. 6977, 1998. doi: https://doi.org/10.1016/S0925-5273(97)00050-9

[23] M. Waris, M.S. Liew, M. F. Khamidi, and A. Idrus, "Criteria for the selection of sustainable onsite construction equipment," International Journal of Sustainable Built Environment, Vol. 3, No. 1, pp. 96-110, 2014. doi: https://doi.org/10.1016/j.ijsbe.2014.06.002

[24] U. Johansson-Sköldberg, J. Woodilla, and M. Çetinkaya, "Design thinking: past, present and possible futures," Creativity and Innovation Management: Special Issue on Design Management, Vol. 22, No. 2, pp. 121-146, 2013. doi: https://doi.org/10.1111/caim.12023

[25] K. Tschimmel, "Design thinking as an effective toolkit for innovation," Paper presented at The XXIII ISPIM Conference: Action for Innovating from Experience Project: Design Thinking - Evolution of the Concept, and of Design Thinking model, Barcelona, Spain, 2012, doi: 10.13140/2.1.2570.3361

[26] K. Dorst, "The core of 'design thinking' and its application," Design Study, Vol. 32, No. 6, pp. 521-532, 2011. doi: https://doi.org/10.1016/j.destud.2011.07.006

[27] T. Brown, and B. Katz, "Change by design," Journal of Production Innovation Management, Vol. 28, No. 3, pp. 381-283, 2011. doi: https://doi.org/10.1111/j.15405885.2011.00806.x

[28] H. Freitas, M. Oliveira, M. Jenkins, and O. Popjoy, "The focus group, a qualitative research method," ISRC, Merrick School of Business, University of Baltimore (MD, EUA), WP ISRC 010298, February 1998 [Working Paper]. Retrieved from http://gianti.ea.ufrgs.br/files/artigos/1998/1998_079_ISRC.pdf

[29] V. Wilson, "Focus groups: A useful qualitative method for educational research?," British Educational Research Journal, Vol. 23, No. 2, pp.209-204, 1997.

[30] E. Colucci, "Focus groups can be fun: The use of activity-oriented questions in focus group discussions," Qualitative Health Research, Vol. 17, No. 10, pp. 1422-1433, 2007. doi: 10.1177/1049732307308129

[31] G. Marden, and L. Reardon, "Questions of governance: Rethinking the study of transportation policy," Transportation Research Part A Policy and Practice, Vol. 101, pp. 238-251, 2017. doi: https://doi.org/10.1016/j.tra.2017.05.008 
[32] S. Komin, "National character in the Thai values orientations," Thailand - United States Educational Foundation, TUSEF/Fulbright, $1990 \quad$ [Online]. Available: http://www.thaisunset.com/downloads/Suntaree\%20Komin\%20Thai\%20National\%20Characte r.pdf [Accessed: May 2020].

[33] Mapping Technology and Training Division, Individually Survey Handbook of the Real-Time Kinematic Global Navigation Satellite System (RTK GNSS) Network, [Online] Bangkok, Thailand, 2018. Available: https://www.dol.go.th/km2/Documents/61RTKY3.pdf

[34] D.J. White, P.K.R. Vennapusa, and H.H. Gieselman, "Field assessment and specification review for roller-integrated compaction monitoring technologies," Advances in Civil Engineering, Vol. 2011, pp.1-15, 2011. doi: https://doi.org/10.1155/2011/783836 